THE NURSERIES OF CHOLERA.

An Address delivered before the Section of Public Medicine of the British Medical Association at Newcastle, August, 1893. By ERNEST HART, D.C.L.,

Chairman of the Parliamentary Bills Committee.

[Owing to the great pressure upon space this address was not published in the British Medical Journal at the time of its delivery. The renewed interest in the subject at the present time, due to the assembly of the International Cholera Conference in Paris to discuss questions in connection with the regulation especially of pilgrim traffic, appears to render the publication of the address in full desirable.]

\section{I.-DIVERSITY OF VIEWS.}

In entering on an investigation of the mode of the diffusion of cholera, one is met at once by the embarrassment that the most diverse views are held and the most opposite opinions expressed on the subject by men who certainly have had no lack of experience of this disease. There is no subject which has been so drowned in experience, in which knowledge has been so dwarfed and stunted by an overgrowth of so-called facts, isolated, unexplained and useless, as this matter of the mode of diffusion of cholera.

The " Providential" Theory.

Nor need we wonder. The great bulk of experience in the matter comes from India, and from that part of India which, from the fact that no year passes, nor any month of any year without the occurrence of the disease, has been aptly called the home of cholera. In that home of cholera the disease, the infection if you like, cannot be traced back from case to to case like a pedigree in a well-kept family tree, but is lost at once in a mongrel crowd of possible ancestors. Cholera exists there on every side. However clear one cause may seem it is equally clear that other causes cannot be eliminated. The observer, bewildered by the omnipresence of the disease, is ready to accept in turn dirt, water, food, temperature, moisture, seasons, flies, and monsoons, as possible modes of origin. Thus arise the Indian opinions that an "epidemic influence," in other words, a " providence" rules these things, and the belief that by no effort could one implant cholera in a district if the epidemic were not moving that way, and that by no effort can one prevent it from arising if this occult, inexplicable entity, this unknown cause, happens to be in operation. A fatalistic notion, a hopeless confession of ignorance and helplessness, just redeemed from being absolutely culpable by the curious coincidence that the same people who hold it do after all believe that somehow or other, in some way which to them is quite inexplicable, good sanitation is a means of preventing cholera-a mixture of sanitary agnosticism and blind belief which it is pitiable to behold. If we want to make progress we must turn from people who are bewildered by statistics and "returns," and seek how cholera behaves when it gets outside and beyond its home, and when, from its isolation, its every movement can be traced. Space will not permit me to give you the details, the complete proof, of the fact that cholera is not a blow from a hidden providence, a vague, imcomprehensible influence, but that it is a filth disease, a malady caused by one man swallowing a poison or contagium which has come from another man; that its power of spreading from man to man depends on man's habit of swallowing substances, chiefly water, which have become contaminated; and that, where men's lives are cleanly and this does not occur, there cholera does not occur either. But I say without hesitation that that is the outcome of European experience, where cholera can be traced and tracked and its outbreaks mapped out free from interference by collateral cases.

Misapprehension of Indian Advisers of the Government.

Few things excite my astonishment more than the way in which men highly placed in the sanitary service of India allow themselves to misapprehend, and even to misstate, the position arrived at in regard to cholera by European investigation, and, it should also be said, by a considerable number of men in India who are now watching Indian outbreaks from the European or "water" standpoint. I read in a well-known book :-

For years now the upholders of the doctrine of the spread of cholera by human intercourse, and by human intercourse alone, have advanced opinions as to what may be expected from the recently increased and much more rapid intercourse between India and England; and in obedience to those theories the restrictions laid on commerce and on dience to those theories the restrictions laid on commerce and on made more and more stringent, till they have become a grievous burden.1

Why confuse direct infection with infection by means of water? Why lump together those who believe in these two very opposite methods of cholera diffusion as people in obedience to whose theories quarantine is maintained? Every reader of a newspaper must know that England, the home of the water theory, is the constant opponent of such proceedings. Another writer, touching on the "main arguments in opposition" to the "water theory" and the "human intercourse theory" says :

In the first place it is remarkable that cholera in India, certainly in the Bengal Presidency, always advances up stream.2

Does he really think that the term "waterborne cholera" means cholera that has got in at the top of a great river like the Ganges, and is floating down stream like a boat or a raft? Again,

In the second place, years will sometimes elapse between epidemics, though it is quite certain the water supply in the interval is just as bad. Did it never occur to him that "badness" of water has nothing to do with it unless the badness results from infection with cholera?

Cholera-laden Ships.

But space does not permit my carrying this matter any further now. A new band of men is springing up who see where truth lies, and who are more likely to be of service in the war against cholera than those whose main delight seems to lie in putting conundrums to their opponents and triumphantly asking, "How can you explain that?" As if things could be explained when only one-half the facts are known. A series of instances in which it can be shown that the drinking of cholera-infected water produced cholera proves the case and pricks the bubble of the monsoon and the occult influence. It is said even that cholera is not carried by ships, but that when cases occur on board some time after departure,

It seems most probable that the ship has passed through. an area where the cholera-producing cause was at work. Such areas beyond all where the cholera-producing cause was at work. Such areas, beyond act question, do exist on land, and it ${ }^{3}$

So we are to imagine that the gnomes or fairies which cause the cholera are web-footed, and paddle about on sea, or are winged and fly across the ocean, and overhaul unfortunate ships. For by whatever means it has been done, ships have certainly carried cholera. Four times Mauritius has been attacked, each time after the arrival of vessels from India with cholera on board; Sunderland in 1831, after a ship arrived from Hamburg; Quebec in 1832, four days after the arrival of the Royalist, on board which cholera had existed on the voyage: Staten Island, New York, in 1848, on arrival of

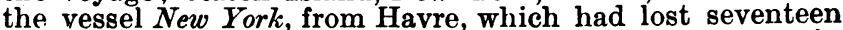
persons from cholera during the voyage; New Orleans in 1848 , three days after the arrival of the ship Swanton, thirteen of whose passengers had died during the voyage. Are all these accidental coincidences, or is this "epidemic influence" of so timid a nature that it seeks a good vessel and the companionship of "human intercourse" before it faces the dangers of the deep?

\section{Cholera a Waterborne Disease.}

What, then, do I mean when I say that cholera is a waterborne disease? I mean that it is caused by a poison which is swallowed, and which in ninety-nine cases out of a hundred is carried to the mouth in water. Within the body this poison grows, multiplies, and in its growth causes the disease, in the course of which it is discharged; then it is ready to take up the other phase of its life, to grow in damp earth, to breed in dirty water, to be washed by rain into watercourses, to. soak through porous soil into wells; in some very rare, un-

1 Surgeon-General Cuningham: "Cholera: What can the State do to 2 Surgeon-Colonel Hamilton: "Cholera." Medical Society of London. 1893.

3 Cuningham, op. cit. 


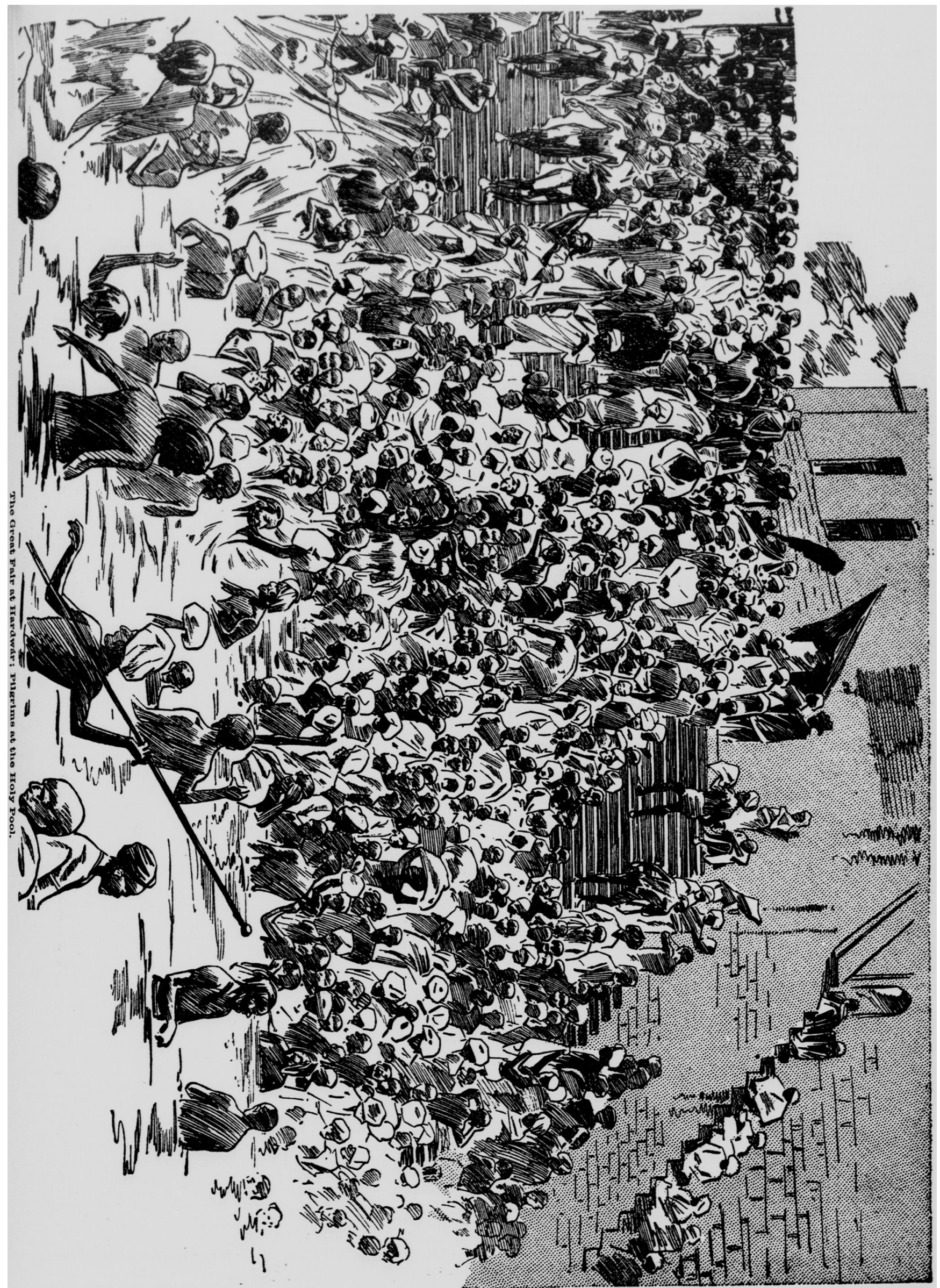


proved cases, perhaps, where cholera is very rife, and filthy habits are overabundant, to be, perhaps, blown by gusts of wind or carried by the hand into food, and thus by one means or another, but in an infinitely larger proportion of cases by means of water, to get round to another person's mouth, to be swallowed and again set up the whole cycle of events. It is not a mere matter of rivers and watershed, but of cooking utensils, drinking cups, water bottles, and especially of cisterns and reservoirs. The disease is waterborne because it is carried by water to the mouth; but that is only the last stage of a journey, circuitous and long, though not often difficult to trace, by which it has travelled from its past to its present host. Inside the body the poison passes, often killing the patient in its passage; outside its course is halting, erratic, various in manner and intensity, depending largely on the physical surroundings in which it finds itself (the soil, the water, the temperature), by which oftentimes it is destroyed, or amid which it dies out.

\section{A Frlte Disease.}

If it lives through its adventures and lands again in the body of a man susceptible to its influence, then again it has its chance, and sets up afresh the old disease. If we fully grasp this conception of the malady, facts fall into their places. The seasonal curve becomes a curve depending on the proper heat and moisture requisite for the development of the most active outside life of the contagion, on thirst causing large drinks, on scanty and therefore foul water, on rains washing accumulated filth into the tanks and watercourses, on a mass of physical causes, and not on the spread of an "epidemic influence." The varied susceptibility of individuals points to varied powers of digesting and thus destroying the contagion, and the greater liability of some nations to be attacked depends on their greater willingness to drink contaminated water. Truly cholera is a filth disease. In the region of the lower Ganges, "the home of cholera," the air, the water, and the soil are never cold, and the ground is often damp, and when it is dry the tanks are foul, so that always there is a fit breeding place for the contagion, and the habits of the people in every way facilitate its entry into their systems. There is nothing strange, then, in cholera becoming endemic in this area; there is a climatic condition, such that the germ can keep alive for considerable periods outside the body, and there is an endemic habit of drinking it freely, but if this habit is broken people can and do live in the very midst of the area free from cholera, and whole districts and communities have thus been endowed with this immunity.

\section{II.-INDIAN FAIRS A SOURCE OF GREAT DANGER.}

Among the habits and customs of the natives of India few are more replete with interest and none more full of the picturesque than the great fairs and pilgrimages which take place at stated periods, attracting people from all parts of the country to one or another spot on the sacred Ganges. From its source down to the sea every foot of Mother Ganga's course is holy ground; to bathe in her waters will wash away sin, to die and be buried on her banks secures free entry to eternal bliss. We need not wonder, then, at the multitude of Hindus who come every year to partake of such blessings. Gangotri, Hardwár, Allahabad, and the Sagar Island are the most sacred spots, and are annually frequented by thousands of pilgrims. Nor are these merely local worshippers, drawn only from the great watershed which the Ganges drains. Wherever the Hindu faith extends, there the legend of the Ganges is believed, and so from every village in India come pilgrims to the holy stream, bringing with them germs of such diseases as may then happen to be epidemic in their midst, or taking back with them to their villages such infection as they may pick up at the holy place. The fair is not only an exchange for merchandise; it becomes a veritable clearing house for contagion, to which each brings what he has and takes away what he can carry. These fairs have always been a source of danger. The Hindu population has for its unit the village. Each village leads a comparatively isolated existence, but at the fairs representatives from the various villages mix freely and a great dissemination of infection takes place.
Pilgrims Carring Contagion.

An account is given by $\mathrm{Dr}$. Simpson, in a report on " $\mathrm{Pil}$ grims and Cholera," of the effect of a large fair or festival held in February, 1891, near Calcutta, in scattering the infection of cholera over the large district from which the pilgrims were drawn. "The evidence is such as to show that to the pilgrims themselves it has been a most disastrous affair; that in many villages the residents who did not attend the bathing festival have suffered on account of the return of the pilgrims; and that in three districts at least a widespread epidemic has been set up." A good example of the way in which pilgrims carry cholera along their track is given by Brigade-Surgeon Coates. The Chief Commissioner of the Central Provinces turned the Bombay pilgrims, who were on their way to Pooree, off one route on to an entirely new one, preventing them from passing through Rajpore and Sumbulpore, because they had always brought cholera with them. The pilgrims were obliged to pass through the Khond country, a part which had always been pointed out as one in which no cholera had ever occurred. Different theories had been framed regarding the soil and climate in explanation of this absence of cholera, but with the advent of the pilgrims all these theories fell to the ground, for cholera broke out and decimated the villages, causing an untold mortality. In Madras it has been officially recorded that the intensity of cholera and the prolongation of its epidemic visitations are largely due to the people going to the divers places where festival ; are held, and to their unnatural mode of living during such seasons. It appears to me that this is a matter in which both reason and history point to the same conclusion, na nely, that these great gatherings of people from all parts are a frequent and recurring source of danger to the countries from which the pilgrims come, and to which they carry back such infection as they meet with.

The Great Fair of Hardwár.

The town of Hardwar is not within the endemic area of cholera, but the water of the Ganges at that spot, just as it escapes cool and clear from its upland home, has a peculiar fascination for the dwellers in the hot and vaporous plains, so that the Hardwar Fair is always largely attended by pilgrims from the area where cholera is always endemic. It has thus frequently happened that this great concourse has been followed by a wide diffusion of the disease outside its bounds. Besides the annual fair (occurring when the sun enters the constellation of Aries), a Kumbh, or great fair, occurs when the planet Jupiter enters the constellation of Aquarius while the sun is in Aries. This only happens once in twelve years, and the occasion is looked upon by Hindus as one of peculiar sanctity. Hence very large numbers then avail themselves of the opportunity of bathing in the holy pool. In 1891, when the last Kumbh fair was held, 800,000 to $1,000,000$ pilgrims assembled in Hardwár, a town which, together with the villages of Kankhal and Jawalapur, only has 29,000 inhabitants. To understand what this means, to appreciate at all the danger of the spread of cholera arising from so vast a gathering, we must bear in mind the habits of the individuals of whom it is composed, and who, entire strangers to each other, carry to their temporary meeting-place the habits of the villages from which they come.

\section{Drinking FodL Water.}

The Hindus are a people with cleanly instincts, but are forced by circumstances into dirty habits. If possible, it is customary for them to bathe every day, and for the women to do so even oftener. And yet during several months there is no rainfall, and they have to trust entirely, both for. drinking and bathing, to water which has been stored in tanks. Horrible as it may appear, it is the ordinary custom of the natives to use for all culinary purposes the water of the public tanks, in which the villagers bathe and wash their clothes, and around which is accumulated every sort of unnamable filth. This habit of drinking foul water is at the root of the constant presence of cholera in India. The natives continually suffer. The Europeans, however, have no "funk" about cholera. They carry with them certain habits of cleanliness, and, being strongly impressed with the necessity of avoiding polluted water, they escape. The comparative, and in some cases almost total, immunity from the 
disease enjoyed nowadays by troops, prisoners, and certain townships is a matter of demonstration; and yet when security begets carelessness the charm is broken, and the hitherto protected communities suffer like the rest. In 1890 the troops at Ranikhet, a hill station, were attacked by cholera, and the characteristic of the outbreak was the large proportionate fatality among the officers of the garrison. The epidemic was in all probability connected with the use for potable purposes of the water of an open trough near the dâk bungalow, where two servants had died. The water of the trough had been used as occasion served for drinking purposes in the married men'sbarracks, where cases occurred, and for special purposes in an aërated water factory from which the officers obtained their supply. Europeans escape so long as they drink clean water; natives also escape when they get into a well-managed gaol where clean water is compulsory; but at these fairs and festivals the very aim and object of their pilgrimage is to bathe in the sacred river and drink of its holy waters. Is it then to be wondered at that they suffer? Amid so great a crowd, largely drawn from the "endemic area," some one or other is sure to have the cholera and to foul the stream, giving to those who drink the fotid water in hope of sanctity an infection which quickly brings about their death. The pilgrims, however, are not the only sufferers. Soon after the festival is over they are scattered to the four winds of heaven, carrying with them the infection. Some drag their weary bodies homewards till they drop by the wayside and die, others by boat or train are carried to distant parts, where, if they do not die en route, they set up fresh foci of disease from which infection spreads among their neighbours.

\section{"A Recurd of Disease and Death.'}

The danger attaching to these vast ga therings at Hardwár, and especially to the great Kumbh fair, is very real. Regarding them a Sanitary Commissioner says that previously to 1867 "very little remains on record, but that little is a record of disease and death." In 1867, and again in 1879, the festival was followed by an outbreak of epidemic cholera, which, on the latter occasion, rapidly extended to the western districts, and in its extreme virulence carried off large numbers of the hill people. Cholera does not become permanently established outside its own endemic area, but it may be carried anywhere, and wherever the habits of the people allow it to take root it will, for la time, ravage and destroy.

An OfFicial Warning.

After two such disastrous experiences the Indian authorities felt a great and natural anxiety as to what would happen when the time came round again in 1891 . Nor was this lessened by seeing that the same conditions which had before been followed by great epidemics were repeating themselves. It had been noted that the appearance of cholera in the spring was always heralded by the occurrence of individual cases of true cholera in the same neighbourhood at the commencement of the cold season preceding. This had been the case in 1866, before the Kumbh of 1867 ; it was also the case in the cold weather of 1878 , and again in the autumn of 1890 cholera was again showing its face. A sharp outbreak took place near Hardwár, at a place near to where it had appeared in 1878 , and in Hardwár itself there had been a good deal of it during the hot weather. All through the winter 1890-31 there was much cholera in the North-Western Provinces, and it was especially severe in the Kumaun hills and along the pilgrim routes below the hills. So grave, in fact, was the outlook that the question of prohibiting the fair, even though a display of force would have been necessary for the purpose, was seriously discussed. Strong opinions were held on the subject, and a communication from the Saharanpur civil surgeon expressed those of many men, officials and others of much experience, when he said that "the most complete sanitary arrangement will be powerless to prevent the spread of cholera should the contemplated fair at Hardwár be permitted to take place."

1II.-THE KUMBH FAIR AT HARDWÁR.

I think I have said enough to show that the position of affairs at Hardwár was critical, and that if the Kumbh fair passed over without evit consequences this could not fairly be looked upon as accidental, but must be attributed to the precautions taken. The steps taken to prevent mischief arising from the Kumbh at Hardwár in 1891 are very fully described in Appendix $E$ to the 2tth Annual Report of the Sanitary Commissioner of the North Western Provinces and Oudh, and to that report I must acknowledge my indebtedness for much that $I$ have to say on the matter. The fair took place in April, 1891. In December, 1890, proceedings began by the construction of seven bridges, by means of which access to the sacred pool from various parts was much facilitated. The whole of the site was then cleared of undergrowth, all filth was scraped away and removed, and arrangements made for the trenching of night soil. A small army of 1,342 sweepers was engaged, and means were taken to prevent their desertion-an event which previous experience had shown to be not unlikely. The whole site was divided into sanitary sections, each with its temporary hospital and its sanitary patrol, every constable of which had his own fixed beat within which he was instructed to: (1) Prevent overcrowding; (2) See to surface cleanliness: (3) Give notice and remove nuisances; (4) Report offenders; (5) Remove those sick of infectious diseases; (6) See to the proper location of animals. The sanitary, police, and medical sections were made to correspond, each section being equipped with a special hospital, a number of constables, sanitary inspectors, an ambulance, and a large staff of conservancy men. Each section was thus complete and self-contained, and was directly responsible to the Sanitary and Deputy Sanitary Commissioners for the conditions of its own area. The members of the sanitary patrol had each their given beats, over which they exercised a constant supervision, acting also as detectives for sickness. The key to the sanitary management of the fair lay in the searching out and rapid removal of all cases of suspicious disease, in the maintenance of perfect cleanliness in the camp, and in the measures taken to prevent all possibility of contamination. Various improvements, however, were made in the conduct of the bathing festival which were no doubt oi great importance.

\section{Confluent Colonies of Microbes.}

The sacred pool, to bathe in which the pilgrims gather together in such multitudes, is approached by a handsome ghat, and is somewhat retired from the rest of the river. It thus soon becomes defiled by the vast concourse of bathers. Dr. Simpson, in describing the scene, says that as the bathing went on the clear stream became a muddy one, and the water collected from any part of it smelt in a few hours offensively, and the micro-organisms developed from it were legion. He sent samples of the water for bacteriological examination to Professor Cunningham, from whose report it is seen that plate cultures made from water above the ghat showed very few microbes; that two to three miles below they were numerous; and that in cultures from all parts of the bathing ghat their numbers were so great as not to form discrete colonies but to become confluent. The water collected from one part also contained comma bacilli. To remedy this condition of affairs the engineer of the Ganges canal arranged for a stream of fresh water to traverse the pool, which was very effective in carrying away the impurities deposited by the bathers, the washings of their bodies and their clothes, the ashes of their deceased relatives, the hair of widows who had been shorn, the decaying flowers offered by pilgrims, and the varied organic filth deposited by a crowd which passed through the sacred waters at the rate of 400 to 500 a minute. Another improvement of great importance, and which, as we shall see later, has a very important bearing on the proceedings at Mecca, was the purification of the Bhim Goda tank about half a mile from Hardwár. 'This tank is peculiarly sacred, and much reverenced by the pilgrims. In it there is an image of Mahadeo, and here all pilgrims must present offerings, bathe, and drink of the water. The tank is a very small one, and had a mud bottom ; the water in it, moreover; could not be renewed, and it may perhaps be imagined what was its condition when many thousands had bathed therein. Dr. Hutcheson recommended that it should be deepened and paved, and that a siphon should be constructed to bring a constant supply of fresh water from the Ganges. This cost a good deal of money, but if it had not been done the slightest 


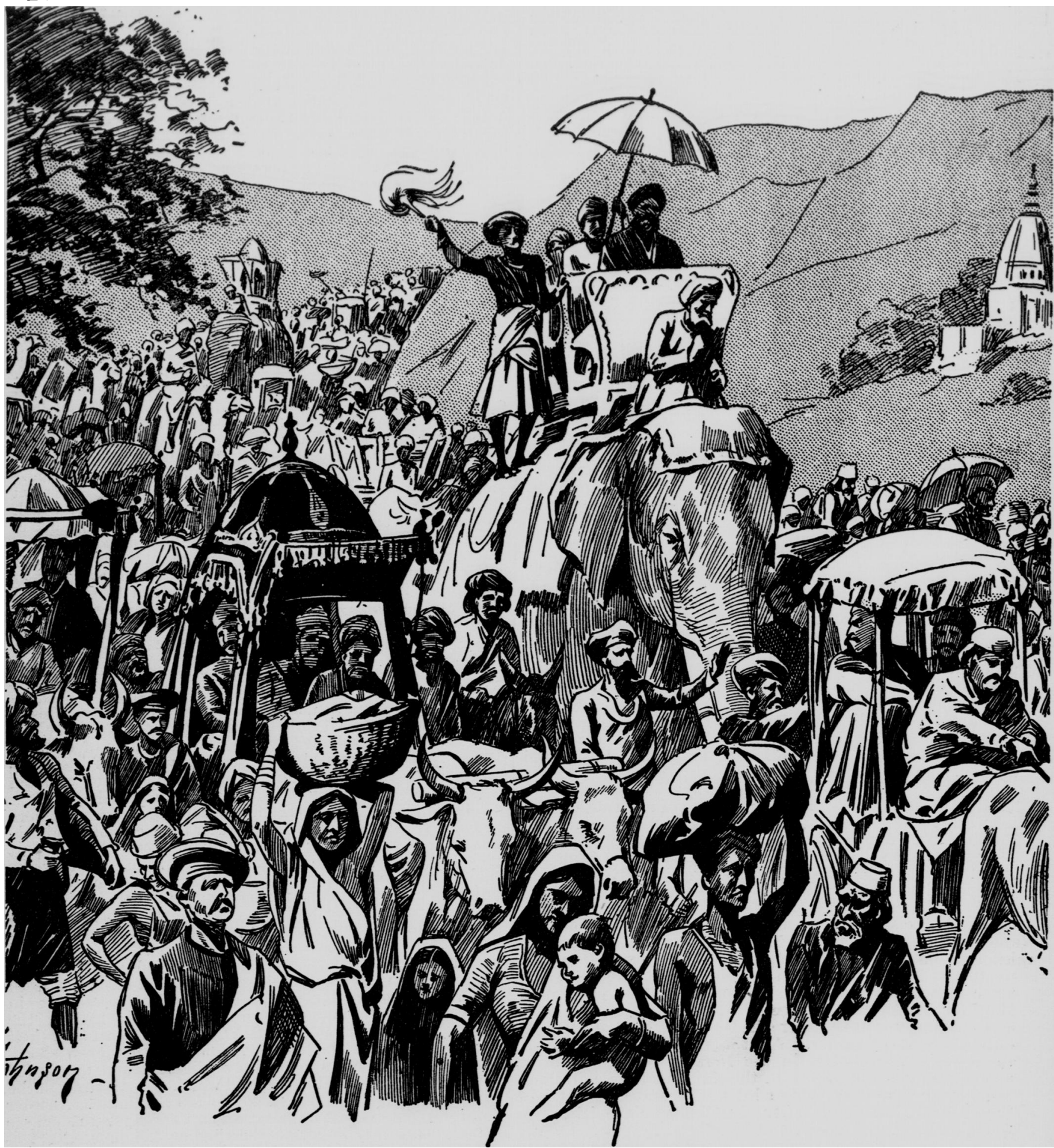

Pilgrims on their way to the Great Fair at Hardwar.

taint of cholera would inevitably have spread the disease among those who drank there.

\section{Mrridas of Moving Creatures.}

At last the time arrived when all these precautions would be tested. The camping ground was invaded by a vast army of pilgrims. By train from distant parts they came in hundreds of thousands, but in the East old ways are not soon supplanted by modern methods, and the great majority came by road. Concentrating from every point, they crowded to- gether as they came nearer to their destination. Rich people on elephants with their attendants, parties with camels to carry their baggage, long trains of bullock carts containing whole families, riders on ponies or on donkeys, intermixed with a vast concourse tramping along on foot, each carrying his bundle on his head, but all alike bringing with them gifts and sins, and hoping to take back their due reward-the sanctity derived from contact with the holy river. Not only were the towns of Hardwar and Kankhal crowded to the utmost, but every available open space was camped upon. 
From April 8th to the 12th there was little space left in Hardwar which was not occupied by a human being. The town on these nights was simply one mass of humanity stretched along roof, verandah, and every open space, and crowding all the available accommodation in dwellings, outhouses, and temporary huts of every description. In the day, Dr. Simpson tells us, "the scene was full of colouring and variety, but that at the ghat baffles description. Such a seething mass of humanity, in constant motion, on the steps, entering and coming out of the sacred pool, could be seen in no other country, and reminded me of the agitation of myriads of moving creatures which one sees under a microscope in a colony of microbes." Hour after hour and day after day they passed through the pool in one continuous stream. It was quite impossible to enforce limits of cubic space for such a crowd. It covered everything, and if it had been allowed to act according to its natural instincts it would have defiled everything, and have wallowed in its own defilement; but it was inspected, drilled, and organised, and although at first there was some resistance, this soon passed away when it was found that if they obeyed in small details the great object of the festival was not interfered with.

\section{A Kumbh Fair withodt an Epidemic.}

There was no house or spot in Hardwár which was not closely scrutinised almost daily; all sullage, water, and refuse was removed from within the town at stated intervals. Dirty water was not allowed to run into the streets or lanes, but was carried right out of the town. No refuse, dirty water, or filth of any sort was allowed even to be trenched or pitted, and still less permitted to accumulate in the town, and both before and during the progress of the fair all night soil, etc., was carefully removed from within the inhabited area. Solution of perchloride of mercury was freely used as required. Sweepers were everywhere. Two hundred and thirty-five sweepers perambulated the roads and camp, cleaning and sweeping all around, and 198 men were formed into eighteen reserve gangs to be sent to any point where there might be extra pressure. Altogether 1,342 sweepers were employed, besides the inspectors and sanitary patrol. The system stood the test. Cholera was prevalent in the eastern districts, and cases were reported from the pilgrim centres of Benares, Fyzabad, and Allahabad during the period of the fair. The pilgrims coming from cholera-infected districts brought the infection with them, and two people died of undoubted cholera at Hardwár during the most crowded period, but they were promptly isolated, and the infection did not spread. No more cases arose in the town or camp, nor did the disease develop on the track of the dispersing pilgrims. And thus we had the novel experience of a Kumbh fair at Hardwár without an epidemic of cholera spreading all over the surrounding country concurrently with the dispersion of the gathering.

THE HYDERABAD CHLOROFORM INQUIRY.

\section{We have been requested to publish the following letter,} which has been addressed by Mr. Furdonji Jamshedji, Private Secretary to his Excellency the Nawab Vikar-ul-Umra, Bahadur, Prime Minister of His Highness the Nizam of Hyderabad, to W. H. Gaskell, M.D., F.R.S., and L. E. Shore, M.D., Cambridge University, and H. A. Hare, M.D., Professor of Therapeutics, and E. Q. Thornton, M.D., Demonstrator of Therapeutics, Jefferson Medical College, Philadelphia. The letter is dated Hyderabad, January, 1894.

SIRS,-I am directed by His Excellency the Nawab Vikar-ul-Umra, Bahadur, to tender to you, and to your assistants, the cordial acknowledgments of His Highness the Nizam's Government for your experiments and reports on Chloroform.

2. In doing so the Minister considers it advisable, in the interests of His Highness the Nizam's Government, to review not only the circumstances which led to the appointment of the Hyderabad Chloroform Commission, but also the finished results of the Commission's, as well as of mission, but also the finished resuls of the arge sum of money has been your own. researches, on all of

3. The Chloroform Commission of 1889 was originated by SurgeonLieutenant-Colonel Lawrie. The object of the Commission was to determine whether or not chloroform has any direct action on the heart, and to set at rest the all-important question, on which the uniform safety of the patient under chloroform depends, "Is it right or wrong to take the pulse as a guide to the effect of chloroform ?

4. It was necessary to settle this question once for all by experiments on animals, because the London school refused to accept as final the clinical statistics put forward for the late. Professor Syme, by his former pupil and house-surgeon, Burgeon-Lieutenant-Colonel Lawrie, to prove that chloroform does not directly affect the heart, and that pulse feeling during chloroformisation is the most common cause of accidental overdosing. These statistics presented an unbroken record extending over forty years, from 1847 to 1889 (and it is still unbroken in 1894), of chloroform administered on Syme's principles in England and in India, with out a death. Syme's principles are best stated in his own words: "We are guided as to the effect, not by the circulation, but entirely by the
respiration; you never see anybody here with his finger on the pulse respiration; you never sed

while The researches of the Hyderabad Commission confirmed Syme's principles. The Commission proved that

(a) Chloroform and shock are incompatibles. It was found to be impossible to stop the action of the heart by any form of shock under chloroform.

(b) In death by chloroform the respiration always stops before the heart, which beats effectively for a considerable time after the breathing has ceased.

(c) The lowering of the blood pressure which is produced by the narcotic action of chloroform is harmless, and cannot be due to weakening of the heart.

(d) Chloroform anæsthesia is free from risk. As long as the breathing is natural and regular, and the inhalation is not continued after

(e) The pulse is never appreciably affected by chloroform, except The pulse is nerer appreciably affected by chloroform,

6. The experiments of the Hyderabad Commission did not satisfy the 6. The experiments of the Hyderabad Commission did not satisfy the
profession. The Commission's evidence of the absence of direct heart profession. The Commission's evidence of the absence of direct heart
failure under chloroform was said to be wholly negative, and further experiments were rightly demanded in order to show the cause or causes of the fall of the blood pressure.

7. These experiments were undertaken on behalf of His Highness the Nizam's Government by two of the greatest living authorities on physiology and physiological therapeutics, Dr. Gaskell in England and Dr. H. Hare by Dr. E. Q. Thornton.

8. The experiments of Drs. Hare and Thornton substantiated those o the Hyderabad Commission. They found that it is not possible "in lower animals (the dog) to cause cardiac death by the freest use of chloroform by inhalation without first causing respiratory arrest." And their report concluded in the following terms: "We agree so heartily with Lawrie's conclusions" (which

9. The value of Dr. Hare's report will be more thoroughly appreciated when it is remembered that it is directly opposed to the conclusions published, only four years ago, by himself and Professor $H$. C. Wood, of Philadelphia; and that it is also altogether opposed to the statement. made by Professor Wood at the Berlin International Medical Congress in made by Professor Wood at the Berlin international Medical congress is August, 1890: We definitely proved that in the dog chloroform has a distinct direct paralysing influence on both respiration and cir

10. The fallacies of Professor Wood's experimental and clinical data were exposed in the Lancet and in the Hyderabad Commission's Report on Chloroform (page 274), and it is satisfactory to note that the report of Drs. Hare and Thornton indicates that they have convinced

11. The cross-circulation experiments devised by Drs. Gaskell and Shore were new to chloroform research. They were of an excessively complicated character, so much so that the difficulties connected with their performance were underrated even by their authors. The cross circulation experiments consisted of two series. The first series was conducted in the Physiological Laboratory at Cambridge by Drs. Gaskell and Shore. It is true that the deductions made by these gentlemen irom their experiments led them to express opinions adverse to the conclusions of the Hyderabad Commission, but the credit for the application of cross-circulation experiments to chloroform investigation belongs exclusively to them. The second series, which was carried much further than the first, was completed in Hyderabad by Dr. Lawrie and Dr. Arthur Chamarette, assisted by students of the Hyderabad Medical School.

12. The object of the cross-circulation experiments was to demonstrate the effects of sending chloroformed blood to the brain alone, or to the heart alone, and His Excellency the Minister is advised that in no other way could the question whether chloroform has a direct action on the heart or not be settled. The chief difficulty connected with the crosscirculation experiments (a difficulty so great as to be nearly prohibitive) consisted in the almost total impracticability of establishing and main taining an efficient cross circulation between two animals. When however, after endless failures this difficulty had been overcome and chloroform was sent to the heart alone, it produced no effect whatever; but when it was sent to the brain alone it produced its usual sequence of evens, namely, the respiration and then death

13. The cross-circulation experiments established the following facts in ddition to those already made good by the Hyderabad Commission

(a) Chloroform has no direct action on the heart or circulation. The heart can only be affected under chloroform by interference with Accordingly, it must befutile and dangerous to take the pulse as a guide to its effect

(b) The lowering of the blood pressure, which is caused by an effective dose of chloroform, is due entirely to its direct narcotic action on the brain, and is a safeguard to the heart, by dilating the smaller arteries and facilitating the flow of blood from the arteria to the venous system, thus diminishing its work and relieving it of strain

Syme's principles of chloroform administration are, therefore, physiologically correct, and there is no longer the shadow of an excuse for the
impotent and dangerous "finger on the pulse while chloroform is given.

14. The Minister observes that Drs. Hare and Thornton express a fear
lest, in certain diseased and enfeebled conditions of the heart, "chloro- 